\title{
New skills for new technologies
}

\author{
from Richard Pearson
}

\section{In some areas - biotechnology being an exception — employers requiring graduate skills seem reluctant to take on candidates with higher degrees.}

THE United Kingdom, like many other countries, is living with a shortage of experienced information technology specialists while demand for these skills continues to grow. Whereas higher education has provided the basic skills and training for most of those entering the new technologies, the role of employers in training and developing new skills is now being emphasized. A UK government committee on the shortage of information technology skills has highlighted the need for a new "partnership between industry and higher education", and the University Grants Committee in its policy proposals for the 1990s stresses the key role to be played by "market signals" and the need for industry to improve its image if suitable students are to be attracted.

What information is available about the pattern of skills needed for the new technologies to help industry, education and students assess their training priorities? The United States has a vast array of studies and data about occupational trends, both past and future, as illustrated in last month's Employment column. In the United Kingdom, however, the only national forecast available does not provide anything like the necessary level of disaggregation: for example, it combines all scientists and engineers into a single category. Reliance therefore has to be placed on a series of ad hoc and often independently generated studies. What, then, do they reveal about the skills needed for the new technologies?

The term "new technologies" is, of course, a label of convenience and many of the constituent technical advances have largely been derived from existing technologies. Thus microelectronics is the miniaturization of electronic components, giving rise to major reductions in size, weight, power consumption and cost - the advantages which allow major new applications. Similarly, biotechnology has been used for centuries in brewing and fermentation, although it is the advances in genetic manipulation and bioprocess technology that have shown its potential in products as diverse as pharmaceuticals and feedstocks. Thus, although these technologies are "new", close examination shows that advances tend to be incremental; their contribution to society is determined as much by their application as by technological breakthroughs. The new technologies are found not only in the "sunrise" industries - they also have an important role to play in revitalizing the "sunset" industries.

Employers' recruitment of staff to apply the new technologies similarly focuses largely on extensions of existing disciplines and emphasizes the key role of undergraduate degree programmes. The electronics industry relies almost exclusively on graduate intake to meet its future needs for professional staff, - the traditional entry routes, of promotion from craft or technician ranks, and part-time study having almost disappeared. Most employers are seeking graduates with broad-based electronics or related skills at a first degree level - even in highly specialized areas, such as semiconductor design and production, the preference is still for a majority of recruits from good quality first degree programmes rather than postgraduate courses.

The picture that emerges for information technology and computing is similar, although a large proportion of the intake to computing functions is of graduates of any discipline. In robotics, the demand is for graduates who can link mechanical, electronic and sof tware skills, and not for fundamental science or a highly specialized degree.

Of all the new technologies, it is in biotechnology that postgraduate qualifications are most relevant. Again the disciplines sought are not new, but built around existing programmes. Here industry is much more closely linked to basic science, and few professional staff in biotechnology research have less than a $\mathrm{PhD}$ and, say, three further years of research experience.

Thus although the new technologies have a high dependency on higher education for their supply of skilled manpower, few of the skills initially sought are highly specific or dedicated to one type of narrow technology, discipline or employer. Rather, they allow for some flexibility in terms of course content and indeed a degree of substitution, for example, between applied physics and electronics. A further advantage is that these demands are also not numerically large when compared with an annual graduate output of around 100,000 per year - electronics and information technology each taking several thousand new graduates each year and biotechnology taking only a few hundred. These needs, however, are not being met.

The pattern and extent of shortages, as measured by vacancies that employers are unable to fill is, of course, greatly influenced by past supply, present need and, particularly, the state of the economy. Thus the serious shortages of electronics and computing skills of 1978-80 abated during the recession but began to reappear in 1984. This year, the main areas of skill shortages have largely been restricted to electronics and computing staff with 3-7 years of experience, together with numerically smaller shortages in areas such as robotics, control, and telecommunications engineering and bioprocess engineering. There is, however, evidence that the incipient shortages of newly qualifying electronics and computing science graduates will soon increase. There are also many areas of work where existing specialists do not have the appropriate personal qualities or motivation to move into line management areas or the application of new technology, where there is a major need for technical skills.

Several initiatives to improve future supply are under way. The number of places on first degree courses in information technology is being increased for the second half of the 1980 s while conversion courses are helping to alleviate shortterm difficulties (see Nature 309, p100; 1984). Industry is also becoming increasingly involved with higher education through the provision of staff and equipment, and in course planning. A broader cross-section of students, however, must be encouraged to apply for the growing number of places, and especially those with the potential to apply such skills in line management and non-technical areas. Women represent a major untapped source of skills; they still fill less than 10 per cent of the places on information courses.

Improvements are already under way to increase the supply of key skills. However, an improved understanding of future manpower needs for all the new, and indeed existing, technologies is still needed to aid planners in government, education and industry, careers advisers and potential entrants. Such changing needs, and the different ways in which they might be met, such as retraining or substitution, also need to be regularly monitored and reviewed in a systematic way; and employment, education and training policies adjusted as appropriate if skill shortages are not to be a recurring problem in the future.

Richard Pearson is at the Institute of Manpower Studies, Mantell Building, University of Sussex, Brighton BNI $9 R F, U K$. 